Matsuzaki H, Tokuhashi Y, Matsumoto F, et al. Problems and solutions of pedicle screw fixation of lumbar spine. Spine 1990; 15:1159-65.

Poussa M, Schlenzka S, Seitsalo S, et al. Surgical treatment of severe isthmic spondylolisthesis in adolescents: reduction or fusion in situ. Spine 1993; 18:894-901.

Roy-Camille R, Roy-Camille M, Demeulenaere C. Ostéosynthese du rachis dorsal lombaire et lombo-sacré par plaques métalliques vissées dans les pédicules vertébraux et les apophyses articulaires. Presse Med 1970; 78:1447-8.

Roy-Camille R, Saillant G, Berteaux D, Salgado V. Osteosynthesis of thoracolumbar spine fractures with metal plates screwed through the vertebral pedicles. Reconstr Surg Traumatol 1976; 15:2-16.
Thalgott JS, LaRocca H, Aebi M, Dwyer AP, Razza BE. Reconstruction of the lumbar spine using AO DCP plate internal fixation. Spine 1989; 14:91-5.

Turner JA, Ersek M, Herron $L$, et al. Patient outcomes after lumbar spinal fusions. JAMA 1992; 268:907-11.

West JL, Ogilvie JW, Bradford DS. Complications of the variable screw plate pedicle screw fixation. Spine 1991; 16:576-9.

Whitecloud TS III, Butler JC, Cohen JL, Candelora PD. Complications with the variable spinal plating system. Spine 1989; 14:472-6.

Zdeblick TA. A prospective, randomized study of lumbar fusion: preliminary results. Spine 1993; 18:983-91.

\title{
Can 'favouring' one leg damage the other?
}

Lay people, and many doctors as well, believe that pain or disability in one leg can stress the other one and produce symptoms in it. In a recent four-year period, 13 such appeals were heard by the Workers' Compensation Appeals Tribunal of Ontario and 11 of them were allowed. In each case, the panel concluded that the compensatable injury to one leg caused the patient to 'favour' it and that this in turn unduly stressed the other normal leg causing or accelerating arthritis in one of its joints (usually the knee). 'Favouring' was thought to have resulted from limping, the need to use crutches or, in one case, from a leg-length discrepancy of $1.25 \mathrm{~cm}$.

We believe that there is no scientific basis for such reasoning. The mechanics of limping are poorly documented in the orthopaedic literature and we have found few references to the effect of a limp on the other leg. To clarify the position for lay adjudicators and the physicians who advise them we reviewed the mechanics of the two basic limps; paralytic and antalgic. In the former the muscles of the weak leg are not strong enough to balance body-weight and the patient walks with a characteristic lurching gait. The trunk, head and arm are displaced towards the affected side, moving the body's centre of gravity directly over the weak leg and thereby reducing the muscle force required to balance the body-weight (Maquet 1976). In the antalgic gait the patient shortens the stance phase by adopting a similar Trendelenburg lurch.

It may seem logical that manoeuvres designed to lessen the load on one leg must increase that on the other,

I. J. Harrington, BSc, P Eng, MD, FRCS C, Associate Professor, Department of Surgery, University of Toronto; and Chief of Surgery, Toronto General Hospital and Head, Division of Orthopaedic Surgery

Suite 317, One Medical Place, 20 Wynford Drive, Don Mills, Ontario, Canada M3C 1J4.

W. R. Harris, MD, FRCS C, Professor (Emeritus), Department of Surgery, University of Toronto; and Consultant, Division of Orthopaedic Surgery, The Toronto Hospital, Western Division

423 Ontario Street, Toronto, Ontario, Canada M5A 2 V9.

(C1994 British Editorial Society of Bone and Joint Surgery 0301-620X/94/4855 $\$ 2.00$

J Bone Joint Surg [Br] 1994; 76-B:519-20. but there is no evidence to support this. Gait studies on patients who had a paralytic and short-leg limp from old poliomyelitis confirmed that the force transmitted in the affected leg was reduced, but that in the opposite leg it was the same as in normal individuals (Harrington 1976, 1992). The findings were similar in patients with an antalgic gait resulting from arthritis (Harrington 1983, 1992).

Paul $(1969,1970)$ showed that the magnitude of hip force in normal individuals varies with body-weight, stride length and walking speed and Harrington (1983) reported similar findings in patients with a limp. A person with a weak or painful leg is likely to walk less briskly than he would if he had normal limbs and the forces in the unaffected limb are therefore likely to be less than those that occur in a normal person. Morrison (1968) offered theoretical reasons why knee loads should be less in elderly or infirm people than in more vigorous individuals.

About 5\% of otherwise normal people have some leg-length discrepancy (up to $4 \mathrm{~cm}$ ) which causes no symptoms. A discrepancy of more than $4 \mathrm{~cm}$ produces a dip on the shorter side during the stance phase but the rhythm of gait is unchanged. Theoretically, a large discrepancy could increase the hip force on the side of the longer leg because of tilting of the pelvis away from the short side at the moment of heel strike but there is no experimental evidence to support this theory.

During treatment of an injured limb the patient often needs to use crutches or a cane and it is widely believed that this may stress the normal leg. When crutches are used, however, there is little change in the rhythm of gait and the force transmitted by the normal leg is increased only by the weight of the crutches. From an engineering point of view the effect of using crutches is similar to standing on one leg, a circumstance in which the forces at the hip and knee are significantly less than those during normal walking. Using a cane may also reduce the force in the normal leg because cane users walk more slowly.

Patients sometimes complain that walking with a plaster cast on one leg brings on symptoms in the other 
and attribute this to the weight of the plaster. A long-leg plaster, however, weighs only two to three pounds and there is no evidence that it significantly increases the load on the normal leg. As has already been explained, the use of crutches lessens the weight borne by both lower legs.

In the days of poliomyelitis, when limping was common, symptoms in the normal leg were seldom attributed to the limp. Amputees rarely develop arthritis in the joints of the surviving limb, despite the fact that no artificial leg can restore a normal gait.

It might be argued that, in a patient with a limp, because the stance phase tends to be prolonged on the normal leg, the time spent transmitting force across its joints is increased. This could have a detrimental effect over the long term but it would probably have to persist for many years to cause a problem. It is unlikely that a limp present for a few weeks or months would have any ill effect.

In summary, there are no hard data to support the belief that 'favouring' one leg adversely affects the other. Such data as we have, taken with the theoretical considerations, suggest that this sequence is unlikely.

IAN J. HARRINGTON W. ROBERT HARRIS

\section{REFERENCES}

Harrington IJ. A bioengineering analysis of force actions at the knee in normal and pathological gait. Biomed Eng 1976; 11:167-72.

Harrington IJ. Static and dynamic loading patterns in knee joints with deformities. J Bone Joint Surg [Am] 1983; 65-A:247-59.

Harrington IJ. Knee joint forces in normal and pathological gait. In: Niwa S, Perren SM, Hattori T, eds. Biomechanics in orthopaedics. Tokyo, etc: Springer-Verlag, 1992:121-46.

Maquet PGJ. Biomechanics of the knee with application to the pathogenesis and the surgical treatment of osteoarthritis. Berlin, etc: SpringerVerlag, 1976.

Morrison JB. Bioengineering analysis of force actions transmitted by the knee joint. Bio-Med Engineering 1968; 3:164-70.

Paul J. Magnitude of forces transmitted at hip and knee joints. In: Wright $\mathrm{V}$, ed. Lubrication and wear in joints. Philadelphia, etc: J. B. Lippincott, 1969:77-97.

Paul JP. The effect of walking speed on the force actions transmitted at the hip and knee joints. Proc R Soc Med 1970; 63:200-2.

\section{Editorial note}

\section{Antiplatelet therapy after hip fracture}

It is unusual for the Journal to publish the description of an experiment before its results are available, but in the case of the invited article by MacMahon et al in this issue the circumstances are special.

First, the subject of the study is of major importance to orthopaedic surgeons. Fracture of the neck of the femur is a mortal illness and its fatality rate has not improved in the last 20 years.

Secondly, the paper exemplifies the potential of meta-analysis to extract more from the sum of several prospectively randomised trials than can be obtained from any of them on their own.

Last, the announcement of the organisation of a large-scale, randomised, prospective trial includes an invitation to orthopaedic surgeons to participate. In an editorial in the Journal in 1992, Dr Chalmers wrote that " . . . orthopaedic surgeons can confidently expect to reap a harvest of evidence of great relevance to their patients: i) by conducting reviews which respect scientific principles (using meta-analysis when appropriate); ii) by recognising genuine areas of therapeutic uncertainty (when systematic reviews do not yield clear evidence and where substantial variations in practice exist between and

C1994 British Editorial Society of Bone and Joint Surgery

0301-620X/94/4862 \$2.00

J Bone Joint Surg [Br] 1994; 76-B:520. within countries); and iii) by collaborating in welldesigned randomised controlled trials of sufficient size to address important questions when uncertainty remains."

The pulmonary embolism prevention (PEP) trial has been designed to provide reliable measurement of the effects of low-dose aspirin on pulmonary embolism, myocardial infarction and stroke after hip fracture. At least 10000 patients need to be recruited. More than 2500 from New Zealand and the United Kingdom have already been enrolled. Participation entails little additional work, no special tests, no alterations to the usual management strategies and no special follow-up. Surgeons who would like to receive further information about joining the trial should contact the organisers at one of the addresses below:

\section{Barbara Farrell Anthony Rodgers PEP Trial Office PEP Trial Office}

Clinical Trial Service Unit Clinical Trials Research Unit The Harkness Building Department of Medicine Radcliffe Infirmary Oxford OX2 6HE, UK Tel: 44-0865-310260 Fax: 44-0865-58817
Auckland Hospital Private Bag 92024 Auckland, New Zealand Tel: 64-9-302 1711

Fax: 64-9-302 1710 